\title{
Organizational Creativity: Building a Business Ba-Haus?
}

\author{
Andy Wilkins ${ }^{1}$, Clive Holtham ${ }^{2}$ \\ ${ }^{1}$ Perspective LLP, Oxford and Senior Honorary Visiting Fellow, Cass Business School, London, UK \\ ${ }^{2}$ Faculty of Management, Cass Business School, City University, London, UK \\ Email: andy@perspectiv.co.uk, c.w.holtham@city.ac.uk
}

Received August 31 ${ }^{\text {st }}$,2012; revised September 28 ${ }^{\text {th }}$, 2012; accepted October $13^{\text {th }}, 2012$

\begin{abstract}
Our focus is on the systemic nature of creativity and the role of business schools in stimulating and enhancing organizational creativity, across all sectors of the economy, particularly those which are not conventionally regarded as "creative" industries. After defining creativity and reviewing a number of frequently occurring "creativity clichés" that are potentially keeping organizational creativity in a rut, we go on to explore some of the key challenges with creativity that need particular focus, including: taking a systemic approach, as well as more attention on "difficult" aspects such as the climate for creativity or creativity "ba". We propose a Systemic Innovation Maturity Framework as a way to conceptualize and organize a way forward in organizations and in business schools. We believe that in a similar way to the Bauhaus of the early 20th century, there needs to be a step change in the way creativity is researched, taught and applied that encompasses a more ecological approach. We believe a more comprehensive, inclusive and useful conception of creativity may result from the consideration of the four dimensions of the framework and their interactions. We wonder: Is it time for a new Business Ba-Haus?
\end{abstract}

Keywords: Creativity; Innovation; Higher Education

\section{Introduction and Purpose}

We believe that in the current economic climate, it is opportune- and maybe even essential- to open up a dialogue about some of the problems with the way creativity is being taught in higher education and applied in business. We aim to explore some of the current dilemmas that we believe exist around the topic of creativity and to propose some ideas on potential ways forward.

In particular, we believe that in a similar way to the Bauhaus of the early 20th century, there needs to be a step change in the way creativity is taught and applied. We need to draw on all of the arts, crafts, informatics, engineering, economics, finance, and the social sciences when it comes to the education and application of creativity.

Historically, much of the focus of creativity research and teaching has been at the individual or small group level. However, there has been a significant strand of interest in organizational creativity through most of the twentieth century, including Wallas (1926), Osborn (1953), Rhodes (1961), upon which later business researchers such as Amabile (1996), Tidd and Bessant (2009), Isaksen and Akkermans (2011) have built.

\section{Definitions and the Language of Creativity, Innovation, Problem Solving, and Change}

Language and terminology are often a block to people working together-paradoxically it appears that the more sophisticated people become, the more divergence in the meaning of words. In this paper, we focus on creativity and so believe we need to be clear about we mean by the term. We acknowledge and accept that our views are not necessarily universal truths or norms but are in alignment with many typical and commonly held definitions in the social sciences. This section therefore looks at some of the main concepts and our approach to finding common ground on which to move forward productively.

Creativity often involves holding more than one viewpoint in mind at a time- what has been referred to as the need to be "ambidextrous" or Janusian: the Roman God Janus had to look in two opposing directions at the same time. As F. Scott Fitzgerald (1945) wrote: "The test of a first-rate intelligence is the ability to hold two opposing ideas in mind at the same time and still retain the ability to function."

For example, in workshops, when we ask people to generate words to describe "creativity", they often respond with words such as new, divergent, exciting, wacky, artists, advertising, music, art and unique. In contrast to this, when we ask what words they associate with "problem solving", they say: analysis, useful, focusing, overcoming difficulties.

Most people acknowledge the tension between these two concepts - the newness, future oriented and aspirational aspects of creativity contrasted with the more here and now, useful and reactive notion of problem solving. Many contemporary definitions and approaches to creativity link this tension between newness and usefulness. Newness for its own sake is not necessarily useful. But put the two together and a powerful approach becomes possible (Isaksen, Dorval, \& Treffinger, 2011).

Creativity has also been described as a special class of problem solving where there is difficulty or ambiguity in problem formulation, there are unclear pathways forward, and a need for ideas to solve the problem as the outcome does not already exist (Newell, Shaw, \& Simon, 1962). Kirton (1994) states that from the cognitive sciences, in order to influence the changing world around us and acquire what we need, we have to solve problems and to solve problems we have to think. Thinking is the process by which we solve problems and it is the same brain function that produces creativity, innovation and change.

Creative thinking and problem solving are also a natural 
phenomenon. We acknowledge that all people have creative potential and all people can solve problems, although not to the same level. And we also believe that, contrary to popular belief, all people change. As Kirton adds: "Things that do not change, fossilise-and humans are not there, yet."

Another contrast we often observe is that people see innovation and change more concerning the outputs, whereas creative thinking and problem solving more concern the people involved and/or the process. We believe that it is possible to have creativity and problem solving without innovation and change but it is not possible to have innovation and change without creativity and problem solving.

We accept that there probably are some differences between creativity, problem solving, innovation, and change but as Kirton explains (1976) many are socially situated. In our experience, we find:

- more technical professions such as engineering tend to use the term problem solving;

- advertising, media and "creative” industries prefer the term creativity;

- change is often used by human resources;

- governments and industry tend to use the term innovation.

For all practical purposes in this paper, we see change and innovation as embracing the concepts of creativity and problem solving as they all closely relate to thinking style and they all involve the elements of newness and usefulness, at least to the creator (Welsch, 1980).

Ultimately, our approach is to conceive creativity, problem solving, innovation, and change as trying to balance moving away from a current perceived reality towards a desired future perceived objective. As Fritz (1993) explains, if there is a tension between what is and what we want, we will seek resolution. For example, if we are hungry (tension) we usually resolve the tension by eating. Tension is always composed of at least two elements in which there is a contrast, discrepancy, gap, a lack, a need, a problem.

\section{The Problems with the Current Situation}

Despite the fast-growing profile and rhetoric concerning creativity at individual, firm and increasingly at national level, it is still the case that creativity as a subject of education and application has not advanced at a pace corresponding to that profile and rhetoric. Indeed, it could even be seen to be stuck in a bit of a rut.

For example, whilst the Cox Review of Creativity in Business (Treasury, 2005) sees exploitation of the nation's creative skills as "vital to the UK's long term economic success" it concluded that: "The success of the creative industries notwithstanding, there is evidence that UK business is not realizing the full potential of applying creativity more widely" and emphazised the need for interdisciplinary teaching in universities.

In this paper we argue that a new approach is needed if the potential of creativity in both academic and business worlds is to be realized. Some of the main aspects of any new emphasis must include:

1) creativity being viewed systemically;

2) creativity being taught across disciplines as well as a discipline in its own right - the discipline of "creatology" (Maghiary-Beck, 1993) — as the Cox Review added, the challenge is: "not just to encourage creative industries, our priority is to encourage all industries to be creative";
3) and any further creativity research needs to be not into individual "components" to increase the innovativeness of organizations but rather in how to help it happen and how the components of the system dynamically interact.

Our ideas are not novel: the holistic formulation of the 4 P's of creativity-people, process, product, press-dates at least back to Rhodes (1961). Isaksen, Dorval and Treffinger (2011) developed the 4 P's by showing that although the themes overlapped, they operationally function together and that in all cases, the context plays a major role. Whilst some may argue that the study of creativity began with the dawn of civilization, many who have reviewed the research on the topic of creativity frequently point in modern times to the presidential address given to the American Psychological Association by Guilford in 1950 . The thesis that creativity should be studied within a new, independent, cross disciplinary framework called "creatology” dates at least back to Isaksen, Murdock, Firestien and Treffinger (1993) in their seminal work: "Understanding and Recognizing Creativity: The Emergence of a Discipline".

However, the promise has largely not been achieved as yet and we believe creativity remains widely misunderstood within academia and business, where it is often perceived as:

1) Something only a minority of people have as distinct from seeing creativity as something everyone has although in varying levels and varying styles;

2) The process for coming up with ideas as opposed to other aspects such as coming up with visions, data, problems, and actions. For example the Cox Review (Treasury, 2005) defined creativity as: "the generation of new ideas-either new ways of looking at existing problems, or of seeing new opportunities, perhaps by exploiting emerging technologies or changes in markets";

3) Mainly about newness and not usefulness;

4) All about "ideas" that are "out there", wacky, paradigm shifting, radical, revolutionary, step changes, discontinuous, out of the box, game changing as distinct from options that are improvements, developments on the existing prevailing paradigm;

5) Related to but not as acceptable in business as the more concrete and organizationally oriented term "innovation";

6) Only involving a few functions or departments such as design, advertising and marketing, and new product development;

7) A side show-not a really important part of a business;

8) Essentially being about generating ideas and tools such brainstorming in which many managers in particular feel they are already well-grounded through everyday experience;

9) Even as a negative term, such as the unfortunate widespread criticism implicit in "creative accounting";

10) A term which has to some extent been explicitly narrowed, as in "creative industries", "creative sector", "creative economy”.

Taking this last point, UK government has been particularly proactive. The Department for Culture Media and Sport (2001) defined the creative industries as: "those industries which have their origin in individual creativity, skill and talent and which have a potential for wealth and job creation through the generation and exploitation of intellectual property".

The 2008 UN Creative Economy Report (2012)further states: "There is no unique definition of the 'creative economy'. It is a subjective concept that is still being shaped. There is, however, growing convergence on a core group of activities and their interactions both in individual countries and at the international level".

We consider it might be more appropriate if the "creative industries" were to be redefined as arts-based industries, and 
“creative economy” as a much broader knowledge-based economy. Creativity is needed as much if not more so in manufacturing, professional service industries and the generality of services, just as much as in the arts-based sectors. There are a number of reasons why the long-standing need for a systemic approach to creativity has not been fulfilled:

1) Firstly, many believe that creativity begins with ideas. This is the most basic misunderstanding relating to creativity. As Ackoff (1974) wrote "We fail more often because we solve the wrong problem than because we get the wrong solution to the right problem."

Detecting the problem is as important as finding the answer. Indeed some argue that defining the problem is more important. For example, in an interview (personal communication) the Global Creative Director of a major Advertising Company suggested that "if we understand the problem well enough, the advert almost writes itself."

2) Much of the thinking and practice about management continues to be fragmented, partly for structural reasons, including the sprawling growth of professions since Rhodes was writing in 1961.

3) The systemic approach itself has endured hard times since its formulation and development in the 1950's and 1960's. Many of the powerful voices of its prophets have become muted as that generation has retired and died.

4) The systemic approach is difficult, and faces obstacles both in conception, and to implement. Von Foerster (1972) has discussed with great clarity that physical science simplifies its task, as it continually fragments problem solving. By contrast societal problem solving is hard, because it cannot afford to fragment, and avoid/ignore key factors. This is what Von Foerster called his "Theorem Number Two":

"The hard sciences are successful because they deal with the soft problems; the soft sciences are struggling because they deal with the hard problems."

5) The difficulty of the systemic approach and the relative growing wealth of the western economies has lead in part, we believe, to what the RSA Tomorrow's Company Inquiry (1995) referred to as "complacency and ignorance of world standards" as one of three prime reasons for blocking global British competitiveness. (An over reliance on financial measures and an adversarial culture are the other two.)

6) The difficulty of the systems approach has also resulted in the maintenance of mental models (Argyris, 1993a) that are often either passed their "use by" date of just plain wrong. As Weick (1969, 2001) succinctly puts it: "Managerial problems persist because managers continue to believe that there are such things as unilateral causation, independent and dependant variables, origins and terminations.”

And as Argyris and Schon (1996) and others have suggested, the irony of improved education is that people may get better and better at explaining why they are right and why they do not need to change their mental models, beliefs, and assumptions. Argyris refers to this process as defensive reasoning and we believe that higher education may put people through a defensive reasoning master class:

"The purpose is to avoid embarrassment or threat, feeling vulnerable or incompetent. In this respect, the master program that most people use is profoundly defensive. Defensive reasoning encourages individuals to keep private the premises, inferences, and conclusions that shape their behavior and to avoid testing them in a truly independent and objective fashion"
(Argyris, 1993b).

John Galbraith (1971) summarizes the point perfectly: "Faced with the choice between changing one's mind and proving that there is no need to do so, almost everyone gets busy on the proof."

8) Lastly recent research by Mckinsey (Aiken \& Keller, 2009) suggests that successful change- - such as the adoption of systems thinking - is less about the persuasiveness of the advocates and more about how receptive a "group, community or society" is to the idea. Over the past 40 years there have been and continue to be advocates of a systems approach and yet we wonder whether society is any more ready to hear the message in the early part of the 21st century?

So what might the conditions be that a society or organization be ready, willing and able to adopt a more systemic thinking approach? To survive and/or to grow in the current times will require some new thinking and action. Maybe the germ of a way forward lies when Robert Flood (1999) writes: "Both Senge's The Fifth Discipline and complexity theory suggest if not fully explain a hidden order, or simplicity in the seemingly impenetrable complexity of the world. Tools of systemic thinking facilitate learning about this order.

\section{Specific Focuses-Management, Leadership, Knowledge, Ba and the Role of Business Schools}

$\mathrm{Xu}$ and Rickards (2007) do not explicitly use the term "systemic", but they do acknowledge the contribution of socioechnical systems thinking with its particular origins at the Tavistock Institute in London (Trist, Emery, \& Murray, 1997). They make a welcome call for what they call the two areas of "management" and "creativity" to be synthesized into "creative management". Of course, this is the very title of a well-known and venerable UK Open University textbook (Henry, 2006).

The authors would argue that the term creative management could be unhelpful in as much as "creative management" or "creative leadership" could take on the same aura as creative accounting and can imply a "whimsical”, "not necessarily legal approach", "corporate entertainment" attitude to management. So we believe that a more productive approach would be to refer to the "management of creativity" or "leadership of creativity".

In the UK, the author who most penetratingly advocated systems thinking was the management cybernetician Stafford Beer (1972), who developed the "Viable System Model". There are also more recent and more widely referenced authors who explicitly acknowledge and incorporate systems thinking into their work, the one with the widest audience probably being, as already mentioned, Peter Senge (1990), for whom indeed it is the "fifth discipline".

$\mathrm{Xu}$ and Rickards (2007) argue there are provisionally three broad "principles of creative management":

- The Universality Principle-creativity is an inherent potential of all human beings;

- The Developmental Principle-potential creativity will become actual creativity under suitable developmental conditions;

- The Environmental Principle-environmental features will influence creativity.

Ruth Noller, Distinguished Service Professor Emeritus of Creative Studies at Buffalo State College, developed an equation for creativity. Her background as a mathematician led her to initiate a creativity formula (Isaksen, Dorval and Treffinger, 2011): 


\section{$\mathrm{C}=\boldsymbol{f}_{\mathrm{a}}(\mathbf{K}, \mathbf{I}, \mathrm{E})$}

where Creativity is a function of Knowledge, Imagination and Evaluation, reflecting an interpersonal attitude toward the beneficial and positive use of creativity.

"The equation is not so precise as to define how many parts of knowledge, imagination or evaluation need to be present for creativity to exist." (Campos, 2000). A child is perceived to be strong in imagination and not as strong in knowledge or evaluation. Likewise, adults may possess more knowledge and evaluation but often lack any confidence or understanding of how tap into their imagination. It can be argued that the most important part of the equation is the letter "a" which represents the need for a positive attitude-free from interpersonal blocks. Without this, sustainable personal creativity cannot flourish.

These interpersonal blocks are climate, a metaphor borrowed from the world of weather and an intervening variable (Ekvall, 1996; Isaksen and Ekvall, 2006) that either helps or hinders the use of resources-see Figure 1. We find in our work that climate is one of those aspects that people intuitively know exists and is important.

In many organizations today there are many initiatives such as growth strategies, innovation schemes and engagement programmes that are not realizing their full potential. It often happens; an organization introduces an initiative with high expectations of improving performance. When the changes fail to take root and produce the intended results, the unfulfilled hopes lead to the introduction of other seemingly promising changes. These, also, ultimately fail to deliver. Ekvall (1987) writes:

"Climate affects organizational and psychological processes such as communication, problem solving, decision making, conflict

\section{Climate is an intervening variable}

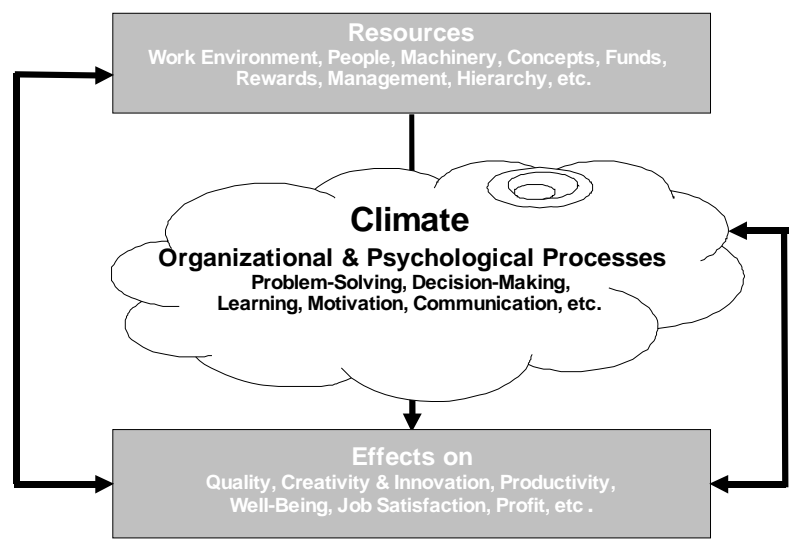

Figure 1.

The outputs of an organization are dependent on its climate. The workplace climate is an intervening variable which has the power to influence processes such as communications, problem-solving, decisionmaking, learning and motivation. Organizations use resources such as people, money, buildings and equipment in their processes and operations. These operations have different effects at different levels of abstraction such as: high or low job satisfaction among employees; high quality or low quality products and services; radically new products or incremental improvements in the existing ones; commercial profit or loss. Climate has an important influence on organizational outcomes but the effects in turn influence both resources and the climate itself. Therefore, organizational climate has much to offer in terms of its ability to help explain the behavior of people in the workplace. handling, learning and motivation. It exerts an influence on the efficiency and productivity of the organization, on its ability to innovate, the job satisfaction and well being its members enjoy. The individual is affected by the climate as a whole, by the general psychological atmosphere, which is relatively stable over time. No single separate influence produces this more lasting effect on behavior and feelings, than the daily exposure to a particular psychological atmosphere. It is because of this overall and lasting effect that the climate concept is of interest and importance to our understanding of organizational life."

We believe that a lack of understanding and focus on climate has been one of the main reasons for the problems of the way creativity is taught and applied. For example, an organization:

- May well have the brightest people but have a climate that doesn't encourage the use of their talents;

- May be attempting to use the latest management tools and processes, but fail to realize full value from the investment;

- That focuses mainly on results and ignores the climate aspects that enable people to achieve them, will decrease the potential for success.

For a relatively small number of organizations creating a healthy, productive and positive climate has become a must do and not a nice to have. Climate has a major effect on people's motivation and their attitude to creativity. Climate is the fundamental psychology of an environment-the recurring practices that create the "atmosphere" of a situation. It is this atmosphere that focuses and motivates behavior. Without changing this, there can be no sustainable change, creativity, or learning and ultimately firms with very poor climates may decline or fall.

\section{Knowledge and Climate and "Ba"}

Knowledge management has considerable overlaps with creativity. As a discipline it is concerned with two broad areas - the sharing of existing knowledge and the creation of new knowledge. The latter area clearly is very dependent on, and closely related to, the whole creativity process. And in our view, the area where this relationship becomes most significant derives from Nonaka and Noboru (1998) when they develop the concept of "ba".

$\mathrm{Ba}$ (roughly equivalent to "place" in English) is a shared space for emerging relationships. It can be a physical ort virtual space. Knowledge, in contrast to information, cannot be separated from the context-it is embedded in ba. To support the process of knowledge creation, a foundation in ba is required.

"In knowledge creation, generation and regeneration of ba is the key, as ba provides the energy, quality and place to perform the individual conversions and to move along the knowledge spiral.” (Nonaka \& Konno, 1998)

Ba then has close links to and overlaps with the Rhodes' 4th P of "press", and Nonaka, Toyama and Konno (2000) demonstrate its pervasiveness in both physical and virtual contexts-Figure 2.

Isaksen and Ekvall's (2006) 9 climate dimensions describe in more detail the quality of the social conditions that moderate success. Climate is the moderating variable on people's ability to be creative and to create and share knowledge.

Historically, "hard" factors such as processes and assets were sufficient to focus on but now investors, companies and managers are asking for a way to measure the "soft" issues like climate. For example, the Council of Institutional Investors 
(CII), which manages over \$1 trillion worth of stocks have started to pay attention to good workplace practices. (Buckingham and Coffman, 2001). So what does a healthy and vibrant ba or climate feel like? Isaksen and Ekvall's 9 dimensions are (2006):

1) Involvement: To what degree are people challenged, involved and committed to making contributions to the success of the organization?

2) Freedom: To what degree are people able to decide how to do their jobs, take independent initiatives and make decisions?

3) Trust: To what degree do people trust each other, as well as feeling safe in being genuinely open and honest with each other?

4) Time: To what degree do people have the time to think, explore and test new ideas and ways of doing things?

5) Playfulness: To what degree do people feel it is OK to have fun when working, be playful and humorous?

6) Conflict: To what degree do people engage in interpersonal conflict, prestige and territory struggles?

7) Support: To what degree do people encourage, warmly receive and professionally support ideas?

8) Debate: To what degree do people frequently share, consider and discuss a variety of viewpoints?

9) Risk Taking: To what degree do people regard failure as an opportunity to learn and feel able to take risks in trying new things?

Because, like the weather, climate is situational, we have real ability to influence the climate that we work in. For example the climate in an organization might be gloomy, but a particular project, group, or interaction with another person, we can create a more sunny, healthy, and productive energy. (The converse also applies, of course.)

Since 1981, Ekvall, Isaksen and others have been developing an instrument to measure the climate for creativity and innovation and the current version is known as the Situational Outlook Questionnaire ${ }^{\circledR}$ (Isaksen \& Ekvall, 2006).

\section{Types of $\mathrm{Ba}$}

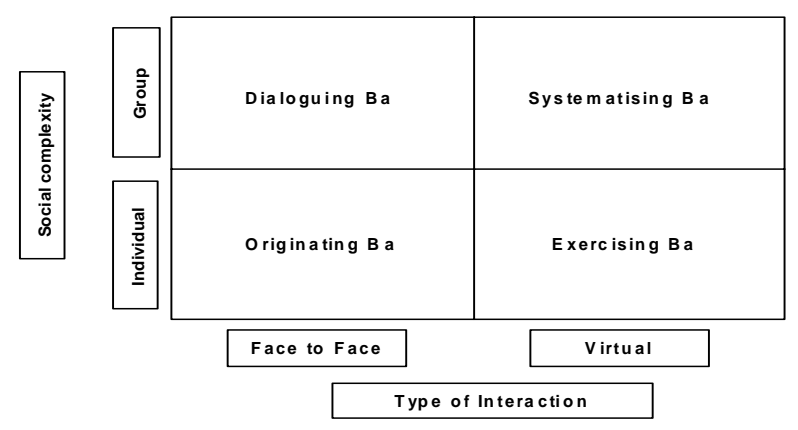

Figure 2.

These four types of Ba highlight the types of interaction that can lead to the creation of new knowledge. Nonaka and Konno characterize Ba on two axes: the degree of social complexity and the type of interaction and the model is helpful in showing how it can be put into practice. Social complexity is viewed as either an individual or group and the type of interaction is labelled either face to face or virtual (through the use of technology). Originating $\mathrm{Ba}$ is where individuals share experiences, emotions and mental models. Interacting $\mathrm{Ba}$ (or Dialoguing $\mathrm{Ba}$ ) is where the tacit knowledge of individuals is made explicit. Systematising $\mathrm{Ba}$ (or Cyber $\mathrm{Ba}$ ) is a place of group interaction in a virtual world where existing explicit knowledge is combined with new explicit knowledge. Exercising $\mathrm{Ba}$ is where explicit knowledge is internalized and made tacit.
Reflecting on these dimensions, people are instantly able to see how their enthusiasm and creativity parallel their work environment. People are readily able to contrast their work, team and organizational situations and describe the climate as either dark and chilly with heavy clouds or grey and cool with light clouds or sunny and warm with a clear blue sky.

Having identified the 9 dimensions that made up the climate, Ekvall and also Isaksen have sought out the factors that affected the climate. They (and others) have found that climate is mainly determined by the behavior of the leader in the particular situation. Other factors included the behavior of colleagues, hard or physical resources such as the environment and capital or money, as well as vision and strategy.

However, the single biggest factor was leadership behavior, which accounted for up to two thirds of the statistical variance (Ekvall \& Ryhammer, 1998; Ekvall, 1997). Certain leadership practices (Ekvall, 1999; Akkermans, Isaksen, \& Isaksen, 2008) stimulate a healthy climate, which in turn creates the conditions for innovation. Therefore, any effort to improve climate will inevitably involve some leadership behavior development.

However, our experience is that many organizations are unwittingly encouraging people to think and behave in ways that are counter productive to creativity and learning. Managers are indeed often rewarded for doing things that have negative effects on innovation and learning.

And also, because climate is situational, we often find that the view of climate is related to the level of the observer. As Prather (1996) explains: "The higher up the organization, the better the environment often appears to be. It is like flying over Barcelona at 30,000 feet-from that height it looks just fine, but at street level you begin to notice the problems because it's at the street level that much of the work gets done."

Prather goes on to conclude: If you are thinking about how to improve the climate in situations that you work or socialise in be sure to begin at the street level.

In terms of the vehicles which may move both academic and business thinking towards the systemic nature of creativity, we are acutely aware of the obstacles. Wilson (2008) points out that: "our education system remains structured in such a way as to reinforce traditional 19th century cultural values, unhelpful stereotypes, the status quo and the 'great divide'.... between creativity and commerce."

Focusing in particular on the academic world, in particular on business schools, creativity tends to be treated as a module or as a topic, often specifically belonging to a particular discipline. It is rarely treated as a theme or as a mindset. But creativity as a theme or mindset cannot be resolved within individual disciplines; it needs to be approached in our view on a transdisciplinary basis, defined by Nicolescu (2001) as: "that which is at once between the disciplines, across the different disciplines, and beyond all discipline."

Ours is by no means a unique argument. Scharmer and Käufer (2000) proposed seven theses to reorientate the 21st Century university, and their thesis 7 saw "universities as birthplaces and hubs for communities of creation", which "do not strive for a type of science which merely reflects the world, but for a science capable of grasping reality by contemplating the underlying forces of its genesis. In such a university, learners and researchers shift from being distant observers to creative co-designers of a praxis in progress-to midwives assisting in the birth of innovation." 
Since disciplines have had such a strong hold on business schools through almost all of their history, it is necessary to look outside management education for suitable higher educational models. Almost certainly the most compelling is the example of the Bauhaus (Holtham, 2007), which we also refer to by its formal original name of the Staatliches Bauhaus. Wick (2001) sets out a masterly review of the Bauhaus as an academic institution, with much that is relevant to teaching and research in any discipline. However, Volkmann and De Cock (2007) warn against simplistically pushing the Bauhaus metaphor too far in business education.

There are continual educational innovations taking place, for example a very interesting grassroots initiative took place at the Rochester Institute of Technology (RIT, 2007). This focused on bringing together the arts, sciences, humanities, and technology, and also seeking collaboration among faculty, students, colleges, and disciplines in co-curricular activities and courses. It also encouraged a dialogue on the role of creativity in teaching, learning, research, and leadership; one of the most impressive dimensions of this was the "unlikely partners" collaboration, involving staff and students in, for example, engineering and poetry working together.

Less frequent are policy-driven initiatives, perhaps the most notable being in Finland. Here, as part of generic university reforms, in 2009 Aalto University was created through a merger of three existing universities: the Helsinki University of Technology (TKK), the Helsinki School of Economics (HSE) and the University of Art and Design Helsinki (TAIK). Markkula and Lappalainen (2008) argued that much of the logic for the new institution lies in is promotion of innovation, and indeed at one point this institution was given the provisional title of "the innovation university".

Even in the absence of mergers across higher institutions, there will continue to be a wide range of other activities which aim to stimulate cross-disciplinary teaching and research. There are numerous individual modules which take innovative approaches, not least those directly and indirectly concerned with creativity. But our concern in specifically with the business school, which has proved relatively resistant to innovative approaches, though some of course do have strong specialisms in creativity, including research departments and extensive knowledge transfer relating to creativity (IEDC-Bled would be a good example).

\section{A New Type of Business School?}

In order to provoke thinking about a new type of business school which would be driven and underpinned by beliefs in creativity and innovation, we have come up with a name, or perhaps more accurately a nickname, which is the "Business ba-haus". We do not regard the ba-haus as working independently or in defiance of ranking and accreditation systems, as argued by Mintzberg (2005). We are working within a less radical approach, such as that advocated by Khurana (2007).

The Staatliches Bauhaus itself had to contend with craft-accreditation systems. The business ba-haus would provide every type of space-physical and virtual-for research and application into the conventional business disciplines and creativity and innovation. Creativity and innovation would be not just be a research focus, they would also be expected in the learning and administrative processes, and particularly in the crucial relationships with external stakeholders.
Its intellectual foundation would not be economics but rather systems thinking, the social and neuro sciences. Transdisciplinarity would form the dominant mindset. The business ba-haus would be able to live with duality and multiplicity and, with "and" being the dominant word:

In terms of research, there is an urgent need to work on the relations between the 4 P's, such as recent work linking people and press (leadership and climate), and on the 4 P's taken as a whole.

In recent research, Akkermans, Isaksen and Isaksen (2008) reviewed relations between leadership and innovation. They concluded: "This study confirmed that there is indeed a strong relationship between leadership and innovative productivity. Furthermore, a leader must focus on the creation of a climate for creativity and innovation in order to truly achieve the innovative outcomes desired. In order to do so, we must be able to know what leadership behaviors help and hinder. This study was an initial attempt to discover these behaviors."

Some device is needed to integrate and connect the $4 \mathrm{P}$ 's, and one possible solution for this has been developed by Straker and Rawlinson (2003), in the form of a Systemic Innovation Maturity Framework. We follow the general approach in our own formulation below (Table 1), but have changed some of the formatting and terminology.

The Systemic Innovation Maturity Framework is a useful model but we cannot simply categorize an organization into a box marked "Level 5" without recognizing the limitation that this type of categorization brings - that the maturity of an organization is an aggregate of its individual members. As a result there will be a distribution of innovation maturity across groups and the organization. The model will therefore be potentially more useful if used for understanding parts of the organization and identifying strategies required to develop or transform individual entities to the next level.

Some caution is needed. Moving through stages takes considerable time, effort and risk especially to the individual who challenges the existing innovation approach. Many struggle for a long time in stage 3 . Some manage to change and progress by moving out of their personal comfort zone and take risks by challenging and changing the existing approach.

The Systemic Innovation Maturity Framework is proposed with the goal of helping to identify the whole picture. As mentioned earlier in this paper, what often happens is an organization introduces an innovation programme with high expectations of improving performance. When the changes fail to take root and produce the intended results, the unfulfilled hopes lead to the introduction of other seemingly promising but incomplete innovation changes. These, also, ultimately fail to deliver.

There are several possible reasons; however, one reason is that the climate for innovation and its relationship with leadership behaviors is not well understood and is often ignored.

As the PwC Innovation and Growth Survey (Davis, Arnett, Gibbons, \& Milton, 2001) found, climate creation and inclusive leadership behaviors were two of the three capabilities that separated the top $20 \%$ from the bottom $20 \%$ of companies, with the third being benign structures or deliberate processes that support innovation.

\section{Conclusion}

The maturity model explains why progress can be made at 
Table 1.

Systemic innovation maturity framework.

\begin{tabular}{lcccc}
\hline \multicolumn{1}{c}{ Stages } & Focus & Approach & Feeling & Character \\
\hline 1. Innocence & Ad hoc & No considered approach & Hope & Ad hoc \\
2. Awareness & Product & Initiate, often via new product development or R \& D & Impatience & Hard \\
3. Hope & Process & Develop processes, methods, and tools & Enthusiasm & Hard \\
4. Competence & People & The more complex, long term and difficult people aspects are addressed & Frustration & Soft \\
5. Excellence & Press (Climate) & Needs understanding of systems, culture and climate, and key aspects of behavior & Enlightenment & Soft \\
\hline
\end{tabular}

the lower levels (individual and small team) of creativity, without impacting much at organizational level. The maturity model heavily emphasizes that even success with the mid-level tools and processes still only achieve part of the potential of creativity. The maximum potential is only achievable by a combination of a systems mindset, systems thinking and fundamental reviews of leadership behavior in helping or hindering the creation of a productive climate. We are under no illusions about the difficulties of achieving levels 4 and 5 in this maturity model. It is difficult and not without risk. But it is a level that is needed for supporting the needs of many organizations in their increasingly competitive 21st century environments.

We are not convinced that conventional business school education will quickly enough promote the systemic approach. Something along the lines of the revolution stimulated and accelerated by the Staatliches Bauhaus in art and design is probably needed. And much of this will hinge on the "ba" or climate.

So we have named our selected vehicle, not wholly facetiously, the business ba-haus. It is possible to create a ba or climate to promote organizational creativity within a formal business school environment. It is possible for schools successfully to practice what they preach, as did the Staatliches Bauhaus. We particularly look to the Systemic Innovation Maturity Framework as a potential organizing system for what yet remains to be achieved in management education more generally. We can re-imagine management education based on systemic thinking. Creativity, both individual and organizational, lies at the very heart of this re-imagination. Schools need a climate which is appropriate for stimulating creativity and, in our view, this might initially only be possible in greenfield locations such as a Business Ba-Haus.

\section{Our Vision for the Ba-Haus}

When we envision the Ba-Haus, we see a place where...

It would have both a strong physical component of classroom/syndicate room learning and a strong virtual component, and the two would be designed together. The aim is to achieve the highest level of engagement with both learning and humans, if not full immersion/flow. "Being there" whether physically or virtually, is held to be of the highest importance.

It is of fundamental importance that there was little or no distinction between academics, administrative staff, visiting fellows and students. All are learners. All are teachers. All are team players. All are practitioners. All are reflective. The aim is collegiality on an almost medieval, Bologna-University style model. The Dean is the President, and the staff and student representatives form the Senate, with stakeholders including all students, being members of Convocation.

The basic design principles of the school's processes draw heavily on Stafford Beer's proposals for the reorganisation of the Manchester Business School in the 1970's (but which were never implemented).

One of the core principles of the school is "practice what we preach”. All decisions on administrative matters will be taken by the School Senate and will be made by direct reference to the academic principles taught at the school and recommended to organisations.

Recruitment will take place for Professors in the Practice of Management, who will be experienced managers with adequate expertise in the theory and learning of management. These will be a mix of full time and part time posts.

Another principle is "lean administration", the explicit minimisation of non-academic expenditures, which had often crept up in some schools to surprisingly high levels. This would use self-service business processes, heavily relying on streamlined Enterprise 2.0 business systems and use of electronic media at all stages.

Turning specifically to the area of creativity, this is highlighted as one of the core domains of the school. It is addressed through the following perspectives:

The philosophy of the whole school is to emphasise creativity and innovation in its own mindset, in its business processes and its incentives and rewards. Using Nonaka's term, the "ba" of the school would be conducive to both the theory and practice of creativity.

All staff, academic and administrative, are expected to keep updated with all developments in creativity and innovation.

Teaching and learning methods of all disciplines will be imbued by approaches that promote creativity for each and every learner, not simply defined narrowly in terms of conventional rational management thinking, but also of the humanities and liberal arts.

Learners will be continually challenged to develop their own understanding of, and competence in, creative approaches to thinking and doing. There is a constant concern with pushing beyond the conventional boundaries of text-based and of electronically-generated communications.

A concern with creativity at individual and small group level is not enough. This has to be complemented by understanding of innovation at business unit and enterprise-wide levels with an emphasis on processes to stimulate innovation, including the right sort of "ba".

The first draft of the Ba-Haus's vision is as follows:

- People find meaning and fulfilment not only in what they do, but the way they do it together; 
- People are respected and appreciated for who they are and the values they hold dear;

- Innovation, creativity and new mistakes are welcomed, learning is encouraged and rewarded;

- Any "elephants in the room" and "the moose under the table” are fearlessly addressed long before they stomp all over trust, creativity and commitment;

- Accountability, self-responsibility and compassion stand side by side;

- People are always honoured with the truth, even when it is scary and difficult;

- People are inspired by visionary leaders who care about them. Yes... care;

- Leaders hold the larger community at heart, honour our children and our future through responsible decisions and actions;

- People thrive on excellence, discipline and execution... a place of extraordinary results.

Our dream at the Ba-Haus is to liberate the creativity inside everyone.

\section{REFERENCES}

Ackoff, R. L. (1974). Redesigning the future: A systems approach to societal problems. New York: John Wiley \& Sons Inc.

Aiken, C., \& Keller, S. (2009). The irrational side of change management. McKinsey Quarterly, 100-109.

Akkermans, H. J. L., Isaksen, S. G., \& Isaksen, E. J. (2008). Leadership for Innovation: A global climate survey-A CRU technical report creativity research unit. Buffalo, NY: The Creative Problem Solving Group, Inc.

Amabile, T. M. (1996). Creativity in context: Update to the social psychology of creativity. Boulder, CO: WestView.

Argyris, C. (1993a). Education for leading-learning. Organizational Dynamics, 21, 5-17. doi:10.1016/0090-2616(93)90067-B

Argyris, C. (1993b). Knowledge for action. A guide to overcoming barriers to organizational change. Camden, NJ: Jossey-Bass.

Argyris, C., \& Schön, D. A. (1996). Organizational learning II. Boston, MA: Addison-Wesley.

Beer, S. (1972). Brain of the firm. Allen lane. London: The Penguin Press.

Buckingham, M., \& Coffman, C. (2001). First, break all the rules: What the world's greatest managers do differently? New York: Simon \& Schuster.

Campos, V. (2000). Contributions to creativity. Unpublished masters project. Buffalo, NY: State University of New York College.

Davis, T., Arnett, A., Gibbons, P., \& Milton, F. (2001). Innovation \& growth survey. London: Price Waterhouse Coopers.

DCMS (The Department for Culture Media and Sport) (2001). Creative industries mapping document 2001 department for culture media and sport. London: The Department for Culture Media and Sport.

Ekvall, G. (1996). Organizational climate for creativity and innovation. European Journal of Work and Organizational Psychology, 5, 105123. doi:10.1080/13594329608414845

Ekvall, G. (1987). The climate metaphor in organizational theory. In B. M. Bass, \& S. D. Drenth (Eds.), Advances in Organizational Psychology (pp. 177-190). Beverly Hills, CA: Sage.

Ekvall, G. (1997). Organizational conditions and levels of creativity. Creativity and Innovation Management, 6, 195-205. doi:10.1111/1467-8691.00070

Ekvall, G., \& Ryhammar, L. (1998). Leadership style, social climate and organizational outcomes: A study of a Swedish university college. Creativity and Innovation Management, 7, 126-130. doi:10.1111/1467-8691.00100

Ekvall, G. (1999). The creative climate: its determinants and effects at a swedish university. Creativity Research Journal, 12, 303-310.

Fitzgerald, F. S. (1945). The crack-up. New York: New Directions
Publishing.

Flood, R. L. (1999). "Rethinking the fifth discipline: Learning within the unknowable. London: Routledge.

Fritz, R. (1993). Creating: A practical guide to the creative process and how to use it to create anything-A work of art, a relationship, a career or a better life. New York: Random House Publishing Group.

Galbraith, J. K. (1971). A contemporary guide to economics, peace and laughter. Boston: New American Library.

Henry, J. (2006). Creative management and development (3rd ed.). London: Sage Publications.

Holtham, C. (2007). "Radical change in management educationWhere the full impact of Stafford Beer may yet take place. 4th Metaphorum Conference. St. Gallen: University of St Gallen. p. 15.

Isaksen, S., Murdock, F., Treffinger, D. (1993). Understanding and recognizing creativity: The emergence of a discipline. Norwood, NJ: Ablex Publishing.

Isaksen S. G., \& Akkermans, H. J. (2011). The creative climate: A leadership lever for innovation. The Journal of Creative Behavior, 45, 161-187.

Isaksen, S. G., Dorval, K. B., \& Treffinger, D. J. (2011). Creative approaches to problem solving. Washington DC: Sage Publications, Inc.

Isaksen, S. G., \& Ekvall, G. (2006). Assessing your context for change: A technical manual for the situational outlook questionnaire-Enhancing performance of organizations, leaders and teams. Buffalo, NY: The Creative Problem Solving Group.

Isaksen, S. G., Puccio, G. J., \& Treffinger, D. J. (1993). An ecological approach to creativity research: Profiling for creative problem solving. Journal of Creative Behavior, 23, 149-170. doi:10.1002/j.2162-6057.1993.tb00704.x

Khurana, R. (2007). From higher aims to hired hands: The social transformation of American business schools and the unfulfilled promise of management as a profession. Princeton, NJ: Princeton University Press.

Kirton, M. J. (1976). Adaptors and innovators: A description and measure. Journal of Applied Psychology, 61, 622-629. doi:10.1037/0021-9010.61.5.622

Kirton, M. J. (1994). Adaptors and innovators: Styles of creativity and problem solving. London: Routledge.

Maghiary-Beck, I. (1993). Creatology: A potential paradigm for an emerging discipline. In S. Isaksen, M. Murdock, R. Firestein, \& D. Treffinger (Eds.), Understanding and recognizing creativity: The emergence of a discipline (p. 48). San Francisco, CA: Ablex Publishing Company.

Markkula, M., \& Lappalainen, P. (2008). New openings in university-industry cooperation: The innovation university as the forerunner of European university reform. SEFI Annual Conference. Rotterdam: Sense Publishers, 109.

Mintzberg, H. (2005). Developing managers not MBA's. London: Financial Times/Prentice Hall.

Newell, A., Shaw J. C., \& Simon H. A. (1962). The process of creative thinking. In H. Gruber, G. Terrell, \& M. Wertheimer (Eds.), Contemporary approaches to creative thinking (pp. 63-119). New York: Atherton Press. doi:10.1037/13117-003

Nicolescu, B. (2001). Manifesto of transdisciplinarity. Albany, NY: State University of New York Press.

Nonaka, I., Konno, N., \& Toyama, R. (1998). Leading knowledge creation: A new framework for dynamic knowledge management. 2nd Annual Knowledge Management Conference. Berkeley, CA: University of California.

Nonaka, I., Konno, N. (1998). The concept of "ba": Building a foundation for knowledge creation. California Management Review, 40, 40-54. doi:10.2307/41165942

Osborn, A. (1953). Applied imagination: Principles and procedures of creative problem solving. New York: Charles Scribner's Sons.

Prather, C. W. (1996). How's your climate for innovation? $R$ \& $D$ Innovator, 5, 6-7.

RSA Inquiry (1995). Tomorrow's company: The role of business in a changing world. London: Final Report.

Rhodes, M. (1961). An analysis of creativity. Phi Delta Kappan, 42, 205-210. 
RIT Creativity and Invention Group (2007). About us. URL (last checked 25 October 2012).

http://www.rit.edu/cla/ciwg/about.php

Scharmer, C. O., Käufer, K. (2000). Universities as the birthplace for the enterpreneuring human being. URL (last checked 25 October 2012).

http://www.ottoscharmer.com/docs/articles/2000_Uni21us.pdf

Senge, P. (1990). The fifth discipline: The art and practice of the learning organization. New York: Currency Doubleday.

Straker, D., \& Rawlinson, G. (2003). How to invent (almost) anything. London: Spiro Press.

Tidd, J., \& Bessant, J. (2009). Managing innovation: Integrating technological, market and organizational change. Chichester: Wiley.

Treasury H. M. (2005). Cox review of creativity in business: Building on the UK's strengths. London: The Stationery Office.

Trist, E. L., Emery, F. E., Murray, H., \& Trist, B. (1997). The social engagement of social science: A tavistock anthology: The socioecological perspective. Philadelphia, PA: University of Pennsylvania Press.

United Nations (2008). Creative economy report. URL (last checked 25 October 2012).

http://www.unctad.org/creative-economy and

http://ssc.undp.org/creative_economy
Volkmann, C., \& De Cock, C. (2007). The bauhaus and the business school: Exploring analogies, resisting imitations. Management Learning, 38, 389-403. doi:10.1177/1350507607080570

Von Foerster, H. (1972). Responsibilities of competence. Journal of Cybernetics, 2, 1-6.

Wallas, G. (1926). The art of thought. London: Watts.

Weick, K. E. (1969). The social psychology of organizing. New York: McGraw Hill.

Welsch, P. K. (1980). The nurturance of creative behavior in educational environments: A comprehensive curriculum approach. Unpublished Doctoral Dissertation, Ann Arbor, MI: University of Michigan.

Wick, R. (2001). Teaching at the bauhaus. Ostfildern: Hatje Cantz Publishers.

Wilson, N. (2008). Whose creativity is it anyway? A critical realist evaluation of managing creativity in the creative economy. URL (last checked 25 October 2012).

http://www.creatifity.com/creatifity/Entr._pubs_files/Wilson\%20for \%20Art\%20of\%20Management\%20Conference\%20July\%2014\%20 2008.pdf

Xu, F. Q., \& Rickards, T. (2007). Creative management: A predicted development from research into creativity and management. 